\title{
Morphological differentiation of a sex chromosome and ribosomal genes in Asellus aquaticus (Crust. Isop.)
}

\author{
E. V. VOLPI, F. PELLICCIA, V. LANZA, M. DI CASTRO* \& A. ROCCHI \\ Dipartimento di Genetica e Biologia Molecolare, Università 'La Sapienza' Roma, and *Centro di Genetica Evoluzionistica \\ del C.N.R. clo Dip. Genet. e Biol. Mol. Università 'La Sapienza' Roma, Italy
}

\begin{abstract}
The karyotype of the isopod crustacean Asellus aquaticus does not normally display any heteromorphic sex chromosome pair. Some of the males in a wild population of $A$. aquaticus collected in the Sarno river near Naples do display a heteromorphic chromosome pair. The heteromorphism is due to the presence of two intercalary heterochromatic areas on one chromosome. This chromosome is inherited through the male line as a normal Y chromosome. The heteromorphic pair has retained the capacity to recombine during meiosis. In-situ hybridization of ribosomal probes, labelled with digoxigenin-dUTP, reveals that ribosomal sequences are associated with both intercalary heterochromatic areas of the heterochromosome. The ribosomal genes are normally telomeric and associated with heterochromatin. After digestion of genomic DNA with $B a m \mathrm{HI}, E c o \mathrm{RI}$ and HindIII restriction endonucleases and hybridization with ribosomal probes, the hybridization patterns of the males with the heterochromosome differ from those of the males without the heterochromosome, as well as from those of the females, which are identical. The possible origin of the morphological differentiation of the heterochromosome, and the causes of the differences in the ribosomal DNA restriction patterns linked to the presence of this chromosome, are discussed.
\end{abstract}

Keywords: Asellus, crustaceans, digoxigenin, heterochromatin, ribosomal genes, sex-chromosome.

\section{Introduction}

The karyotype of the isopod crustacean Asellus aquaticus $(2 n=16)$ in both sexes consists of eight homomorphic chromosome pairs. The first six are very similar in shape and the last two morphologically identifiable (Montalenti \& Rocchi, 1964). A heteromorphic chromosome pair has recently been identified in a certain number of males in a wild population collected in the Sarno river near Naples. This heteromorphism was detected by $\mathrm{C}$-banding and consists of the presence of two heterochromatin areas on a metacentric chromosome, located one on each arm in an interstitial position (heterochromosome) (Rocchi et al., 1980). The heterochromosome is inherited only by the male offspring of males which have it. That seems to indicate that we are dealing with an early stage in the morphological differentiation of a sex chromosome (Rocchi et al., 1984).

Correspondence: Professor Angela Rocchi, Dipartimento di Genetica e Biologia Molecolare, Università 'La Sapienza', 00185 Roma, Italy.
No useful form of G- or R-banding can be achieved on $A$. aquaticus chromosomes, even using $\mathrm{BrdU}(\mathrm{Di}$ Castro et al., 1979; Rocchi et al., 1980).

On some chromosomes, C-banding reveals a number of polymorphic terminal areas which vary from individual to individual and are usually associated with the nucleolus organizer regions (NORs). The NORs identified by $\mathrm{N}$ - and Ag-banding are located in terminal positions on the chromosome pair number 7 and on a larger pair. A large number of specimens have additional terminals NORs (Di Castro et al., 1977, 1983).

All the heterochromatic areas, including the intercalary areas of the heterochromosome, fluoresce brightly after staining with the GC-specific fluorochrome, chromomycin A3, and remain dark after staining with quinacrine mustard. Electron microscope observation at the pachytene stage during meiosis found the spermatocytes displaying eight synaptinemic complexes with fully paired lateral axes (Rocchi et al., 1989). On optical microscope examination the heteromorphic pair, detected by chromomycin $\mathrm{A} 3$, is also 
seen to be fully paired. At metaphase I this pair often appears to be associated terminally and is separated at an early stage (Rocchi et al., 1984).

In-situ hybridization experiments and hybridization experiments on genomic DNA of males and females, using a probe rich in the tetranucleotide GATA, revealed no sex-linked patterns (Pelliccia et al., 1991).

In the present work we used probes containing the ribosomal sequences $18 \mathrm{~S}, 5.8 \mathrm{~S}$ and $28 \mathrm{~S}$ to test males and females from the Sarno river population, both with Southern and in-situ hybridization.

Our results show that variant hybridization patterns of the ribosomal probes may be detected in the genomic enzyme-restricted DNA of males with the heterochromosome, and that ribosomal sequences are associated with the intercalary heterochromatic areas of the heterochromosome.

\section{Materials and methods}

The research was carried out on a population of Asellus aquaticus collected from the Sarno river near Naples. The DNA was extracted at least three times separately from batches of 30 male and female individuals, as previously described (Pelliccia et al., 1991). Before some DNA extractions the males were cytologically analysed to detect the presence of the heterochromosome.

Samples of DNA $(2 \mu \mathrm{g})$ were digested with the restriction endonucleases BamHI, EcoRI or HindIII (Boehringer, Mannheim) for $4 \mathrm{~h}$ at $37^{\circ} \mathrm{C}$ at a ratio of roughly $10 \mathrm{U} \mu \mathrm{g}^{-1}$ DNA. Lambda HindIII and lambda EcoRI-HindIII fragments were used as size markers. Electrophoresis was performed on horizontal agarose gels $(0.7-0.9$ per cent). Transfer to nylon filters (Hybond N, Amersham) was carried out by Southern blotting.

Three probes were used: the $\mathrm{pXcr} 7 \mathrm{DNA}$, a plasmid pBR322 containing a complete genetic unit of $X$. laevis rDNA; a 1286 bp fragment at the $3^{\prime}$ end of the $X$. laevis $28 \mathrm{~S}$ sequences (X128S) (both these probes were kindly supplied by I. Bozzoni, Rome, Italy); a 1,506 bp fragment, which includes most of the $18 \mathrm{~S}$ sequence, isolated by digesting $\mathrm{pXcr} 7$ DNA with restriction enzyme $X b a \mathrm{I}(\mathrm{X} 118 \mathrm{~S})$.

The probes were labelled by the random priming technique using $\left(\alpha^{32} \mathrm{P}\right)$ dATP (Amersham, spec. act. 3,000 $\left.\mathrm{Ci} \mathrm{mmol}^{-1}\right)$.

Prehybridization was carried out at $68^{\circ} \mathrm{C}$ for about $16 \mathrm{~h}$ in $5 \times$ Denhardt's $6 \times \mathrm{SSC}, 0.5$ per cent SDS. Hybridization was performed at the same temperature for $24-48 \mathrm{~h}$ in the same solution, adding the labelled denatured probe and $25 \mu \mathrm{g} \mathrm{ml}^{-1}$ of denatured $E$. coli DNA. The filters were washed with $2 \times \mathrm{SSC}, 0.1$ per cent SDS followed by $0.5 \times$ SSC, 0.1 per cent SDS at $68^{\circ} \mathrm{C}$. Wet filters were exposed to Kodak XAR5 autoradiography film at $-70^{\circ} \mathrm{C}$ for $1-7$ days.

Cytological preparations were obtained from squashes of testes of male individuals $1.5 \mathrm{~h}$ after colchicine injection (conc. 0.05 per cent). The testes were fixed and squashed in 45 per cent acetic acid. Slides were ethanol-dehydrated and stored desiccated at $-20^{\circ} \mathrm{C}$ for several days.

pXcr 7 was amplified for in-situ hybridization. The HindIII complete ribosomal DNA insert was isolated and labelled with digoxigenin-dUTP using the random priming technique (kit supplied by Boehringer, Mannheim). In-situ hybridization and cytochemical detection were carried out as previously described (Pelliccia et al., 1991). The slides were photographed, treated with 3:1 (vol./vol.) methanol:acetic acid and then stained with $\left(50 \mu \mathrm{g} \mathrm{ml}^{-1}\right)$ chromomycin $\mathrm{A} 3 /$ methyl green to reveal the heterochromatic areas.

\section{Results}

Hybridization with the $\mathrm{pXcr} 7$ clone, when the BamHI, EcoRI or HindIII restriction enzymes are used, reveals rDNA restriction patterns that are different from males with the heterochromosome, males without the heterochromosome and females; the latter two being the same. For all three enzymes used the difference is related to the presence of fragments in the DNA of males with the heterochromosome, which are absent in the DNA of females and males without the heterochromosome. These fragments are as follows: three for the BamHI enzyme (about 3.5, 2.8 and $1.5 \mathrm{~kb}$ long); one for the EcoRI enzyme (about $15 \mathrm{~kb}$ long) and one for the Hind III enzyme (about $21 \mathrm{~kb}$ long) (Fig. 1).

The use of the X118S and X128S sequences as probes gives rise to complementary patterns which are in agreement with the previous observations (Fig. 2).

When the complete digoxigenin-dUTP labelled ribosomal insert is hybridized in situ with cells of males, the two intercalary heterochromatic areas of the heterochromosome always appear heavily labelled (Fig. 3) and some telomeric regions are also found to be labelled. In the cells of individuals that lack the heterochromosome, no chromosome is found to have interstitial labelling. A nucleolus was sometimes observed in association with the two heterochromatic areas of the heterochromosome in prometaphase cells. The chromosomes of the heteromorphic chromosome pair, observed on 200 cells in meiotic metaphase I derived from 33 individuals, appear with equal frequency ( 19 per cent) as precociously separated (Fig. 4a), terminally associated with both telomeres to form a ring tetrad (Fig. 4c), or as a cross-shaped tetrad in 


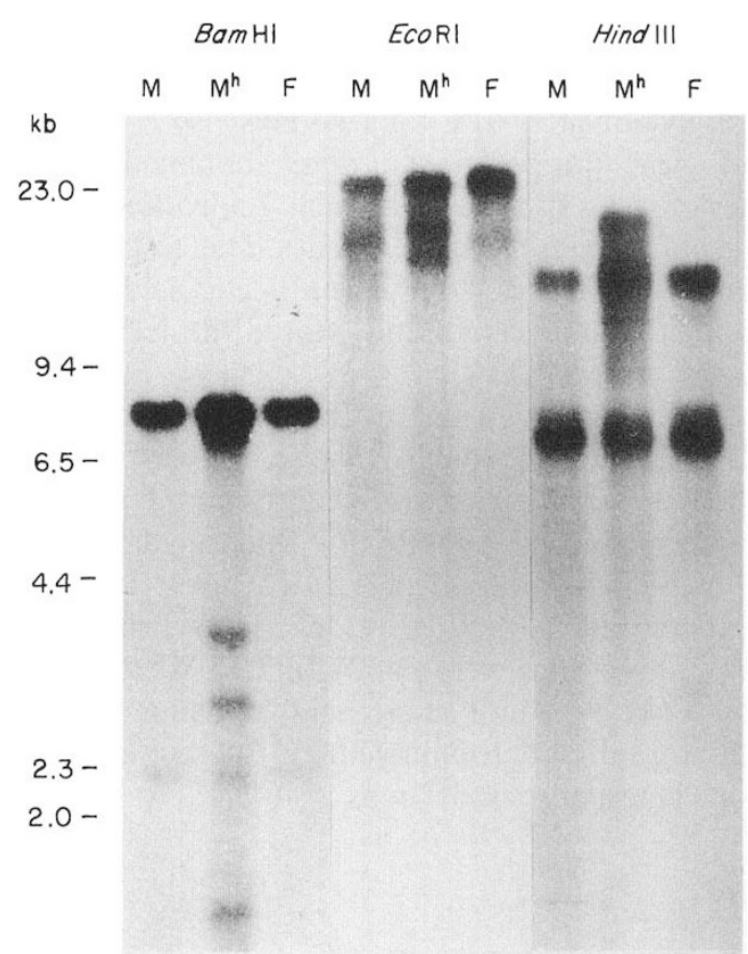

Fig. 1 Southern blot hybridization of genomic DNA of males without the heterochromosome $(\mathbf{M})$, males with the heterochromosome $\left(\mathbf{M}^{\mathrm{h}}\right)$ and females $(\mathrm{F})$ digested with BamHI, Eco RI and HindIII. The probe was the ${ }^{32} \mathrm{P}$-labelled pXcr7.

which the exchange takes place in the chromosome region distal to one of the two intercalary heterochromatic areas (Fig. 4b); or else, more frequently $(42$ per cent), they appear as terminally associated with a telomere. Only one cell exhibited a chiasma in the chromosome region lying between the two heterochromatic areas (Fig. 4c). A precociously separated chromosome pair is also observed in the 7 per cent of the cells of individuals lacking the heterochromosome.

\section{Discussion}

It is held by some authors that accumulation of heterochromatin on a chromosome involved in sex determination is possible as a result of the absence or low frequency of exchange between this chromosome and its 'homologue'. The heteromorphism thus acquired by the chromosome pair helps to inhibit the frequency of exchange and further favours morphological differentiation (Muller, 1918; Bull, 1983; Charlesworth, 1991). In $A$. aquaticus, at meiotic metaphase I, the heteromorphic chromosome pair often appears to be precociously separated or terminally associated. In some cells, however, the same pair is involved in nonterminal exchanges that occur in the chromosome

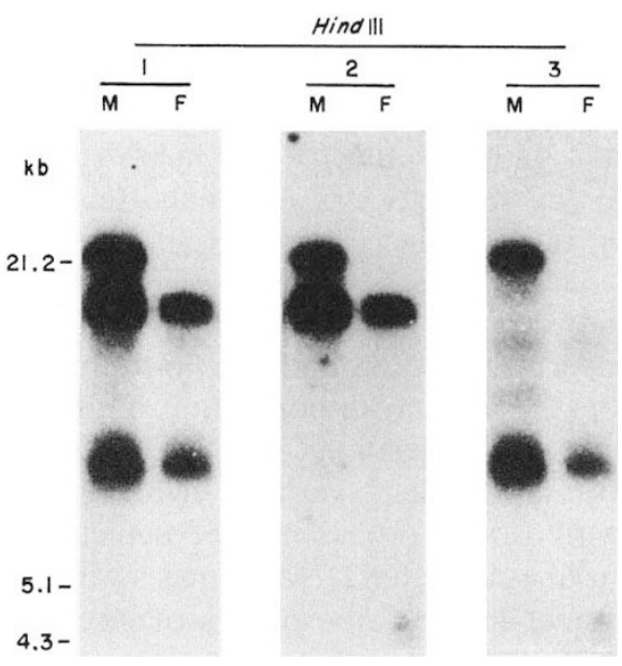

Fig. 2 Southern blot hybridization of genomic DNA of pooled males with and without the heterochromosome $(\mathbf{M})$ and females $(\mathrm{F})$ digested with HindIII. The same filter was hybridized consecutively with three ${ }^{32} \mathrm{P}$-labelled different probes: pXcr7 (lanes 1), X118S (lanes 2) and X128S (lanes 3).
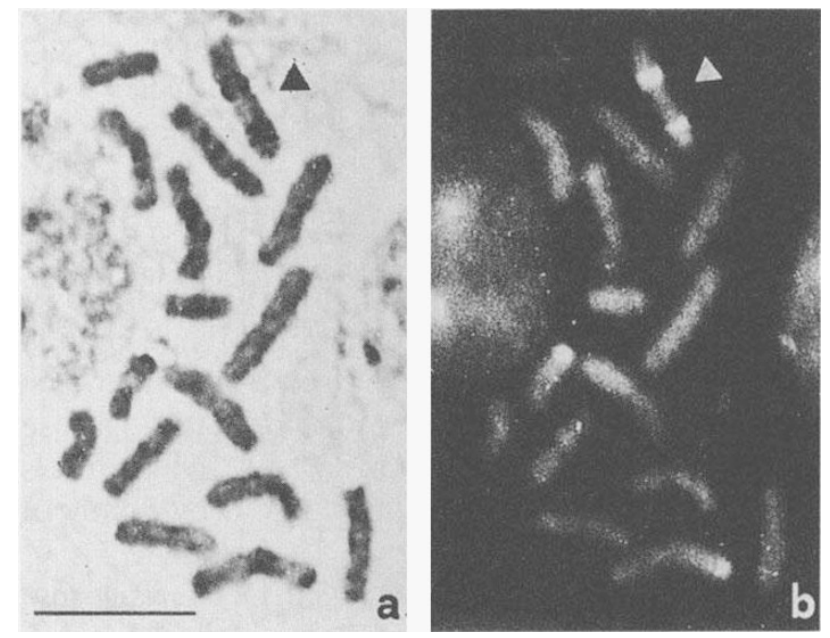

Fig. 3 Spermatogonial metaphase of a male with the heterochromosome hybridized in situ with the digoxigenin-dUTP labelled HindIII complete ribosomal insert of $\mathrm{pXcr} 7$ (a). The same metaphase stained with chromomycin $\mathrm{A}_{3}$ /methyl green (b). The arrowheads indicate the heterochromosome. $\mathrm{Bar}=10 \mu \mathrm{m}$.

regions distal to the heterochromatic regions. Crossing-over seldom takes place in the region between the two heterochromatic areas. These exchanges obviously give rise to heterochromosomes with a single heterochromatic region which are in fact found in a small percentage of both male and female individuals (Rocchi et al., 1984). All this suggests that the heteromorphic pair has retained a high degree of genetic homology and 

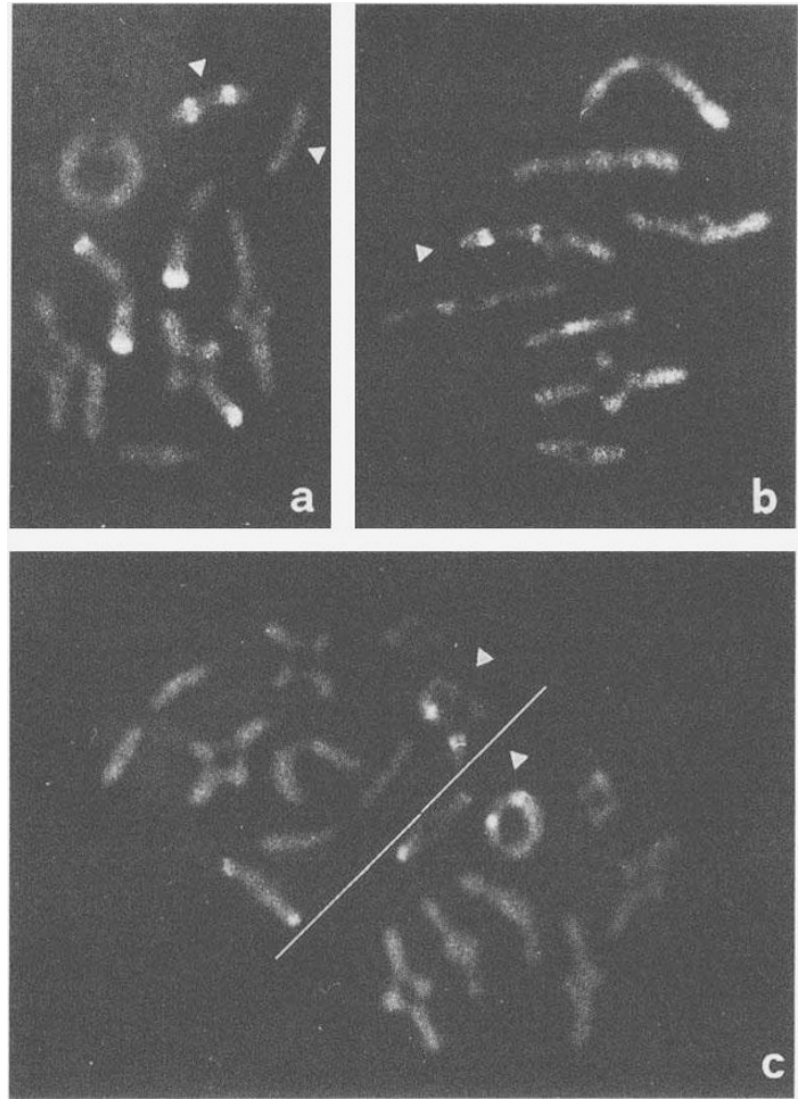

Fig. 4 Meiotic I metaphases of males with the heterochromosome stained with chromomycin $\mathrm{A}_{3} /$ methyl green. The heteromorphic pair appears precociously separated (a), as a cross-shaped tetrad (b), recombined in the chromosomal region between the two heterochromatic areas and terminally associated to form a ring tetrad (c).

that important rearrangements of the linear order of the DNA sequences have not taken place in the heterochromosome.

It thus seems possible to rule out any likelihood of the intercalary heterochromatic areas of the heterochromosome having originated by simple chromosomal inversions bringing the telomeric heterochromatic areas and the ribosomal genes associated with them into interstitial positions.

Several different hypotheses have been advanced to account for the appearance of heterochromatic areas in different organisms. These hypotheses basically involve processes of transposition and amplification of sequences or the transformation of dysfunctional genes (e.g. Lucchesi, 1978; Flavell, 1982).

In the case of $A$. aquaticus, in order to account for the molecular mechanism underlying the evolution of a sex heteromorphic pair, it is necessary to bear in mind the following: the heterochromosome seems longer than the 'homologue'; as shown in the present paper, the intercalary heterochromatic areas of the heterochromosome contain ribosomal genes; the NORs are telomeric and usually associated with heterochromatin; the heterochromatin associated with NORs has the same colorimetric properties, using base specific fluorochromes, as the intercalary heterochromatin of the heterochromosome.

In view of this evidence, it could be justifiably postulated that, telomeric heterochromatic and ribosomal sequences may have been transferred to interstitial sites on non-homologous chromosome arms.

A role for telomeres in the initiation of intercalary C-bands has been suggested by several authors (for a brief review see Schweizer \& Loidl, 1987). According to these authors the transfer of sequences, which is probably replicative, would require proximity between a telomere and an interstitial chromosome region. This proximity is thought to be due to the telophasic chromosome retaining their so-called 'Rabe-orientation' during the interphase. This orientation is believed to bring telomeres and interstitial chromosomal regions into contact in the case of chromosomal arms of different lengths.

Analysis of the restriction patterns of the ribosomal DNA reveals differences linked to the presence of the heterochromosome. In fact, the males that possess this chromosome have patterns that are different from those of the males that lack it. The latter have the same patterns as the females. The hypothesis that a variant ribosomal sequence is present in males with the heterochromosome and associated with the intercalary heterochromatin, appears extremely plausible in view of the restriction patterns obtained after HindIII enzyme digestions. In fact, the approximately $21 \mathrm{~kb}$ fragment, present only in males with the heterochromosome, could be the result of the summing of the two fragments of about 14 and $7 \mathrm{~kb}$, respectively, present in all the individuals. The variant sequence would thus be the result of the loss of a HindIII restriction site. Conversely, the restriction patterns obtained after digestion with BamHI and EcoRI enzymes cannot be interpreted in such a way. Furthermore, with the latter two enzymes, the strength of the signal of the supernumerary fragments present in males with heterochromosome, does not point to multi-copy sequences. It may be postulated that the supernumerary bands in these two cases are due to the different nature of the sequences flanking the ribosomal genes associated with the intercalary heterochromatic regions in comparison with those of the ribosomal genes of the NORs. From our results, although in the absence of any specific probe, it may be postulated that the repeating ribosomal unit in $A$. aquaticus is at least $23-\mathrm{kb}$ long. 


\section{Acknowledgements}

This work was supported by Ministero della Pubblica Istruzione and by the Consiglio Nazionale delle Ricerche. We would like to thank the Foundation Cenci Balognetti for supplying restriction enzymes.

\section{References}

BULL, J. J. 1983. Evolution of Sex Determining Mechanisms. Benjamin/Cummings Publishing Company, Menlo Park, CA.

CHARLESWORTH, B. 1991. The evolution of sex chromosomes. Science, 251, 1030-1033.

DI CASTRO, M., PRANTERA, G., CIPRIANl, L. AND ROCCHI, A. 1983. Silver staining analysis of nucleolar organizer activity during spermatogenesis of Asellus aquaticus (Crustacea, Isopoda). Genetica, 60, 163-166.

DI CASTRO, M., PRANTERA, G., MARCHETTI, E. AND ROCCHI, A. 1977. $\mathrm{N}$-banding and nucleolus organizers in Asellus aquaticus (Crust. Isop). Heredity, 39, 259-262.

DI CASTRO, M., PRANTERA, G., MARCHETTI, E. AND ROCCHI, A. 1979. Characterization of the chromatin of Asellus aquaticus (Crust. Isop.) by treatment in vivo with BrdU and Hoechst 33258. Caryologia, 32, 81-88.

FLAVELL, R. 1982. Sequence amplification, deletion and rearrangement: major sources of variation during species divergence. In: Dover, G. A. and Flavell, R. B. (eds) Genome Evolution, Academic Press, New York, pp. 301-323.

LUCCHESI, J. C. 1978. Gene dosage compensation and the evolution of sex chromosome. Science, 202, 711-716.

MONTALENTI, G. AND ROCCH1, A. 1964. Note cariologiche sul genere Asellus. Boll. Zool., 31, 341-348.

MULLER, H. J. 1918. Genetic variability, twin hybrids and constant hybrids, in a case of balanced lethal factors. Genetics, 3, 422-499.

PELLICCIA, F., DI CASTRO, M., LANZA, V., VOLPI, E. V. AND ROCCHI, A. 1991. GATA repeats in the genome of Asellus aquaticus (Crustacea Isopoda). Chromosoma, 100, 152-155.

ROCCHI, A., LANZA, V. AND DI CASTRO, M. 1989. Surface spreading of synaptonemal complexes in three isopod crustacean species. Genetica, 78, 125-132.

ROCCHI, A., PRANTERA, G. AND DI CASTRO, M. 1980. A study of the heterochromatin of Asellus aquaticus (Crust. Isop.). Caryologia, 33, 401-409.

ROCCHI, A., PRANTERA, G., LANZA, V. AND DI CASTRO, M. 1984. Incipient sex chromosome differentiation in an isopod crustacean species, Asellus aquaticus. Chromosoma, 89, 193-196.

SCHWEIZER, D. AND LOIDL, J. 1987. A model for heterochromatin dispersion and the evolution of C-band patterns. In: Stahl, A., Luciani, J. M. and Vagner-Capodanno, A. M. (eds) Chromosomes Today, Vol. 9, Allen \& Unwin, London, pp. 61-74. 